\title{
Procedimientos diagnósticos, características clínicas y asesoramiento en la fibrosis quística
}

\author{
Kris De Boeck \\ Departamento de Pediatría, Universidad de Lovaina, Lovaina, Bélgica
}

\begin{abstract}
Palabras clave
Fibrosis quística - Prueba del sudor • Mutación del RTFQ • Medición de la diferencia de potencial nasal - Síndrome de la pérdida de sal $\cdot$ Pseudomonas aeruginosa $\cdot$ Insuficiencia pancreática $\cdot$ Infertilidad masculina
\end{abstract}

\section{Extracto}

La mayoría de los pacientes con diagnóstico final de fibrosis quística (FQ) presenta síntomas clásicos, como íleo meconial, incapacidad de medrar y tos recurrente o persistente, en los primeros meses de vida. Las manifestaciones patológicas son evidentes, progresivas y afectan a diferentes sistemas de órganos. En estos pacientes, la prueba diagnóstica estándar es la prueba del sudor. Una concentración de cloruros en el sudor $>60 \mathrm{mmol} / \mathrm{I}$ confirma el diagnóstico de sospecha clínica. Desde el descubrimiento del gen RTFQ (regulador de la conductancia transmembránica de la FQ), ha llegado a ser evidente que el espectro clínico es amplio. Se ha demostrado que diversas categorías de pacientes son portadores de dos mutaciones de RTFQ: pacientes con FQ clásica; pacientes con síntomas más leves e inicio de la enfermedad durante la adolescencia o incluso la edad adulta; pacientes con una única característica clínica, como por ejemplo, pancreatitis recurrente, colangitis esclerosante, bronquiectasia 'idiopática' o infertilidad masculina. Las dos últimas categorías se describen como FQ atípica o no clásica. Es muy importante que estos pacientes sepan que, si bien no sufren de FQ clásica, tienen un factor de riesgo para desarrollar una enfermedad similar a la FQ que justifica el seguimiento intermitente por parte de médicos familiarizados con el muy amplio espectro de la enfermedad. En pacientes con FQ clásica, la infección sinopulmonar bacteriana progresiva y la inflamación con exacerbaciones intermitentes son las manifestaciones patológicas más típicas. El $90 \%$ de los pacientes presentan insuficiencia pancreática. Los hombres postpuberales son estériles. Durante toda su vida, los pacientes afectados de FQ pueden presentar manifestaciones y complicaciones patológicas en los senos, los pulmones, el páncreas, el hígado, el intestino, el esófago, los huesos, las articulaciones, etc. La mezcla compleja de posibles manifestaciones patológicas confiere un carácter único a cada paciente. A medida que el paciente se hace mayor, el número de complicaciones tiende a incrementarse y su estado físico, a empeorar. Numerosos pacientes con FQ adultos jóvenes presentan un menoscabo de la tolerancia al esfuerzo debido a la neumopatía avanzada; el $20 \%$ presenta diabetes mellitus relacionada con FQ. La FQ clásica es un trastorno potencialmente mortal e, incluso con el tratamiento y el seguimiento más intensivos, la mediana de supervivencia actual gira en torno a 34 años. Este hecho genera un enorme estrés psicológico a los pacientes y sus familias. El asesoramiento para prevenir la recurrencia de la enfermedad en hermanos y en la familia ampliada es importante y complejo.

Copyright ๑ 2006 Nestec Ltd., Vevey/S. Karger AG, Basel

\section{KARGER}

Fax +4161306 1234

E-Mail karger@karger.ch

www.karger.com
C 2006 Nestec Ltd., Vevey/S. Karger AG, Basel

0252-8185/06/0643-0119\$23.50/0

Accesible online en:

www.karger.com/ans
Prof. Dr. K. De Boeck

Department of Pediatrics

Herestraat 49, BE-3000 Leuven (Belgium)

Tel. +32 16343820 , Fax +32 16343842

E-Mail christiane.deboeck@uz.kuleuven.ac.be 


\section{Introducción}

La fibrosis quística (FQ) es el trastorno hereditario potencialmente mortal más corriente en la raza blanca. Su incidencia en los recién nacidos varía considerablemente según la etnia de la población estudiada. Desde el descubrimiento del gen $R T F Q$ (regulador de la conductancia transmembránica de la FQ), ha resultado evidente que la FQ aparece en cualquier población estudiada hasta la fecha, y que la incidencia ha sido más bien subestimada en las razas distintas de la blanca [1].

La FQ es una enfermedad hereditaria recesiva autosómica, causada por una sola mutación en cada uno de los genes que codifica la proteína RTFQ. La FQ es una enfermedad multiorgánica. Los síntomas son consecuencia del deficiente transporte de cloruros a través de los epitelios de las glándulas exocrinas, debido a la ausencia o la disfunción del canal del cloruros del RTFQ activado por AMPc [2].

La inmensa mayoría de pacientes presenta manifestaciones patológicas en el momento del nacimiento o durante los primeros meses de vida. No plantean ningún reto diagnóstico siempre que éste se considere y se realice una prueba del sudor en un laboratorio experimentado. Algunos pacientes presentan tipos de enfermedad mucho más leves y plantean un reto diagnóstico muy importante. Estos pacientes pueden tener síntomas variables y, en ellos, el resultado de la prueba del sudor será a menudo poco concluyente. Las pruebas diagnósticas adicionales contribuyen a llegar a una conclusión; es decir, una búsqueda de dos mutaciones del RTFQ causantes de enfermedad o la prueba fisiológica de la disfunción de la proteína RTFQ [3].

\section{Síntomas que conducen al diagnóstico de FQ}

Dado que la FQ es la enfermedad hereditaria grave más corriente en la raza blanca, debe considerarse frecuentemente en el diagnóstico diferencial de lactantes con síntomas recurrentes persistentes de diferentes tipos. De hecho, numerosos síntomas pueden ser la primera manifestación de FQ.

Después del nacimiento, el vómito y la ausencia de deposiciones aparece en el 10 al 15\% de los lactantes con FQ [4]. El íleo meconial es tan específico de la FQ que el diagnóstico apenas puede pasar inadvertido. Una manifestación neonatal menos conocida es la ictericia colestásica prolongada [5]. La presentación más corriente es la incapacidad para medrar debido a insuficiencia pancreática exocrina, a menudo en combinación con tos crónica [6]. Por otra parte, la digestión normal puede conservarse durante meses a años [7].

La tos recurrente o persistente y las infecciones torácicas recurrentes o crónicas pueden comenzar durante la lactancia y la infancia. El inicio de la tos crónica es desencadenado a menudo por una infección vírica, como la causada por el virus sincitial respiratorio [8].

Los síndromes de la pérdida de sal se observan principalmente en climas cálidos. Un golpe de calor con deshidratación y desequilibrio electrolítico debido a pérdida de sal excesiva puede conducir al diagnóstico [9]. Sin embargo, también en climas templados, los lactantes pueden presentar apatía, ingestión deficiente, vómito, ganancia de peso deficiente y poliuria de tipo Bartter debido a alcalosis hipoclorémica e hipopotasemia secundaria a la ingestión insuficiente de sal [9].

Cuando el diagnóstico pasa inadvertido en la primera infancia pueden aparecer complicaciones patológicas que, en última instancia, permiten el establecimiento del diagnóstico: dedos en palillo de tambor, bronquiectasia, sinusitis crónica, pólipos nasales, cirrosis hepática, hematemesis, hemoptisis, etc. No obstante, la lista de manifestaciones que conducen al diagnóstico de FQ es larga (tabla 1). Un deseo de embarazo insatisfecho en una pareja, que propicia la detección de azospermia en el varón debido a ausencia bilateral del vas deferens es el ejemplo clásico de un fenotipo FQ atípico [10; Cutting, p. 113].

Cualquier médico incluiría FQ en su diagnóstico diferencial para un infante que presente con retraso en crecimiento e infecciones respiratorias recurrentes. Sin embargo, corrientemente, el diagnóstico pasa todavía inadvertido o se establece con retraso, incluso en pacientes con síntomas clásicos. Los motivos de este hecho pueden ser múltiples. Los padres expresan la molestia principal de modos diferentes. En lugar de afirmar: 'Mi hijo o hija come mucho, evacúa deposiciones grasas y no aumenta de peso' pueden decir: 'Mi hijo o hija está inquieto/a y es difícil de calmar'. Los padres pueden consultar con médicos diferentes en lugar de regresar al mismo médico con un problema sin resolver. Puede perseguirse un solo síntoma secundario a malabsorción en lugar de interpretar el conjunto del cuadro: edema y anemia, con derivación a un nefrólogo pediátrico; distensión, hepatomegalia y alimentación difícil, con derivación al cardiólogo pediátrico; hematomas, con derivación al oncólogo pediátrico; erupción perianal y perioral, con derivación al dermatólogo; anemia y hemólisis, con derivación al hematólogo pediátrico. Todas estas situaciones han sido descritas [11]. Además, frecuentemente, los niños no presentan 
Tabla 1. Manifestaciones clínicas indicativas de FQ

\begin{tabular}{|c|c|}
\hline Muy indicativas & Indicativas pero menos específicas \\
\hline \multicolumn{2}{|l|}{ Manifestaciones gastrointestinales } \\
\hline \multirow[t]{4}{*}{$\begin{array}{l}\text { Íleo meconial } \\
\text { Insuficiencia pancreática exocrina en niños }\end{array}$} & $\begin{array}{l}\text { Incapacidad para medrar } \\
\text { Hipoproteinemia } \\
\text { Deficiencia de vitaminas liposolubles }\end{array}$ \\
\hline & $\begin{array}{l}\text { Síndrome de obstrucción intestinal distal } \\
\text { Prolapso rectal }\end{array}$ \\
\hline & $\begin{array}{l}\text { Cirrosis biliar } \\
\text { Hipertensión portal } \\
\text { Colelitiasis en niños sin trastorno hemolítico } \\
\text { Colangitis esclerosante primaria }\end{array}$ \\
\hline & $\begin{array}{l}\text { Insuficiencia pancreática exocrina en adultos } \\
\text { Pancreatitis recurrente }\end{array}$ \\
\hline \multicolumn{2}{|l|}{ Manifestaciones sinopulmonares } \\
\hline \multirow{5}{*}{$\begin{array}{l}\text { Infección respiratoria persistente por } \\
\text { Pseudomonas aeruginosa mucoide } \\
\text { Bronquiectasia en ambos lóbulos superiores } \\
\text { Infección respiratoria persistente por } \\
\text { Burkholderia cepacia } \\
\text { Pólipos nasales en niños }\end{array}$} & $\begin{array}{l}\text { Infecciones respiratorias persistentes o recurrentes por } \\
\text { Staphylococcus aureus, P. aeruginosa, Achromobacter } \\
\text { xylosoxidans o Haemophilus influenzae }\end{array}$ \\
\hline & $\begin{array}{l}\text { Signos radiológicos de bronquiectasia, artelectasia, distensión } \\
\text { o infiltrados persistentes en la radiografía de tórax }\end{array}$ \\
\hline & $\begin{array}{l}\text { Hemoptisis asociada a neumopatía difusa distinta de } \\
\text { tuberculosis o vasculitis }\end{array}$ \\
\hline & $\begin{array}{l}\text { Tos crónica y/o productiva } \\
\text { Aspergilosis broncopulmonar alérgica }\end{array}$ \\
\hline & $\begin{array}{l}\text { Pólipos nasales en adultos } \\
\text { Pruebas radiológicas de pansinusitis crónica }\end{array}$ \\
\hline \multicolumn{2}{|l|}{ Otras } \\
\hline $\begin{array}{l}\text { Alcalosis hipoclorémica en ausencia de vómito } \\
\text { Ausencia bilateral congénita del vas deferens }\end{array}$ & $\begin{array}{l}\text { Dedos en palillo de tambor } \\
\text { Osteopenia/osteoporosis con menos de } 40 \text { años de edad } \\
\text { Diabetes atípica }\end{array}$ \\
\hline
\end{tabular}

De Boeck y cols. [55] con autorización del BMJ Publishing Group.

una enfermedad aguda. Aunque la tos asociada a infección crónica de las vías respiratorias no es inicialmente acusada, es, sin embargo, muy persistente. Lenta y progresivamente aumenta el malestar respiratorio. Numerosos niños se presentan al pediatra general con infecciones torácicas recurrentes. El facultativo puede obviar el diagnóstico de FQ porque el aspecto del niño es demasiado sano o no presenta incapacidad para medrar. El índice de sospecha debe ser elevado en niños con una molestia crónica. Sin duda, todos los niños que pueden producir esputos, que presentan infiltrados torácicos recurrentes, en quienes la tos sólo mejora transitoriamente con tratamiento antibiótico, que no dejan de toser durante el vera- no, en quienes el tratamiento antiasmático es insatisfactorio o que muestran dedos en palillos de tambor, deben ser explorados mediante la prueba del sudor.

El diagnóstico precoz es muy importante para retrasar la progresión de la enfermedad. En consecuencia, la detección sistemática neonatal es recomendable en países que puedan afrontar el coste y/o especialmente en regiones con una edad media elevada en el momento del diagnóstico [12]. Sin embargo, la detección sistemática neonatal no carece de problemas, dado que también se detectarán heterocigotos y niños con diagnósticos dudosos [13]. 


\section{Pruebas diagnósticas específicas de FQ}

La confirmación diagnóstica de FQ puede realizarse por medio de la prueba del sudor, por análisis del ADN de mutaciones del RTFQ o por bioanálisis del RTFQ. En ámbitos donde esté disponible, la prueba fiable del sudor de Gibson y Cooke [14] es la prueba diagnóstica inicial más apropiada debido a su elevado rendimiento: el $98 \%$ de los pacientes norteamericanos afectados de FQ presentan una prueba del sudor positiva [15]. El objetivo de una prueba de ADN del RTFQ 'de primera línea' estriba en detectar las mutaciones del RTFQ causantes de FQ más prevalentes en la población de la que procede el paciente; es decir, mutaciones del $R T F Q$ con una frecuencia $>0,5 \%$. En la mayoría de las poblaciones esto propiciará la detección de dos mutaciones en el 80 al 95\% de los pacientes [1]. En pacientes con manifestaciones patológicas atípicas la prueba del sudor es a menudo equívoca. Serán necesarias pruebas diagnósticas adicionales para confirmar el diagnóstico: análisis de mutaciones del RTFQ y, en ocasiones, bioanálisis del RTFQ.

\section{Prueba del sudor}

Una prueba del sudor realizada con precisión conlleva un elevado rendimiento diagnóstico. No obstante, esta prueba 'sencilla' exige una gran experiencia y una atención meticulosa al detalle. En numerosos laboratorios los errores son probables, dado que se realiza un número insuficiente de pruebas por demasiados técnicos de laboratorio diferentes [16]. La prueba del sudor mediante la iontoforesis cuantitativa de pilocarpina, elaborada por Gibson y Cooke [14] en 1959, sigue siendo la prueba de elección. Tras la estimulación con pilocarpina, debe recogerse el sudor durante 30 minutos sobre una gasa o papel filtro pobre en cloruro sódico, pesado previamente $[3,14$, $17,18]$. Se requiere una tasa de sudor mínima de $1 \mathrm{~g} / \mathrm{m}^{2}$ del área de superficie corporal/min; por lo tanto, un sudor que pese 50 a $100 \mathrm{mg}$ es adecuado.

Una concentración de cloruros en el sudor $>60 \mathrm{mmol} /$ 1 confirma el diagnóstico de FQ en pacientes con síntomas clínicos indicativos. El valor límite de $60 \mathrm{mmol} / \mathrm{l}$ discrimina fiablemente entre sujetos normales y pacientes con FQ [19]. Un valor de cloruros $>60 \mathrm{mmol} / \mathrm{l}$ se asocia casi siempre a FQ. Sin embargo, existen algunas excepciones: se han descrito valores $>60 \mathrm{mmol} / \mathrm{l}$ en un cierto número de trastornos cutáneos inusitados y en procesos endocrinos o metabólicos raros que pueden distinguirse fácilmente de la FQ. Incluso entonces, éstos están relacionados principalmente con las historias clínicas. El sudor normal contiene $<60 \mathrm{mmol} / \mathrm{l}$ de cloruros y sodio, habi- tualmente incluso $<30 \mathrm{mmol} / \mathrm{l}$ [20]. La prueba del sudor puede realizarse a partir de la tercera semana de vida, siempre que el lactante pese más de $3 \mathrm{~kg}$, esté normalmente hidratado y no presente ninguna enfermedad significativa. Para detalles adicionales sobre la prueba del sudor remitimos a informes de consenso [3, 17, 21].

Una proporción de sujetos portadores de dos mutaciones, una en cada uno de los genes $R T F Q$, presentan una concentración de cloruros en el sudor $<60 \mathrm{mmol} / 1$ [22, 23]. No existe en realidad un valor límite inferior absoluto de la concentración de cloruros en el sudor que pueda excluir casos de FQ atípicos [22]; sin embargo, la mayoría de los autores explora a pacientes con concentraciones de cloruros entre 40 y $60 \mathrm{mmol} / \mathrm{l}$. Uno de los estudios se centró en pacientes con concentraciones de cloruros entre 30 y $60 \mathrm{mmol} / 1$ [20], que representaban alrededor del $4 \%$ de las personas sintomáticas sometidas a una prueba del sudor. Se comprobó subsiguientemente que el $23 \%$ de estos pacientes portaban dos mutaciones del RTFQ [20].

\section{Identificación de mutaciones en el gen RTFQ}

El gen $R T F Q$, localizado en el brazo largo del cromosoma 7, codifica la proteína RTFQ. Esta proteína transmembránica actúa como un canal de cloruros mediado por AMPc; está dotado de numerosas funciones siendo una de las importantes la regulación del balance de iones y agua a través de los epitelios [2; Donaldson y Boucher, páginas 103 a 109].

Se han identificado más de 1.500 mutaciones del RTFQ [24]. Se han comunicado más de 1.000 mutaciones en pacientes con síntomas de FQ. El resto guarda relación con las enfermedades más leves relacionadas con el RTFQ o no causan enfermedades en absoluto [24]. Para varias mutaciones, es decir, la mayoría de las mutaciones de clase I (mutaciones sin sentido, mutaciones de sitio de empalme y deleciones/inserciones fuera de estructura), la naturaleza causante de FQ es evidente. En cuanto al resto de mutaciones, sólo estudios funcionales determinan sin lugar a duda si se trata de mutaciones causantes de FQ. Hasta la fecha, estos estudios se han efectuado únicamente para la mayoría de las mutaciones del RTFQ corrientes. Una rara mutación de sentido erróneo, hallada después de una detección sistemática completa del gen RTFQ, puede ser un polimorfismo o una mutación causante de FQ [Cutting, p. 113].

La FQ es una enfermedad recesiva autosómica, lo que significa que un paciente con FQ presenta una mutación causante de la enfermedad en ambos genes RTFQ. Un paciente afectado de FQ puede ser homocigótico cuando es portador de una mutación $R T F Q$ idéntica en ambos alelos 
$R T F Q$, o heterocigótico compuesto cuando es portador de dos mutaciones de RTFQ diferentes.

La frecuencia de las mutaciones del RTFQ difiere entre las poblaciones [1]. F508del es con mucho la mutación más corriente, y se halla en el 70\% o más de los cromosomas de FQ en las poblaciones de Europa septentrional. Se observan frecuencias muy inferiores de F508del en las poblaciones de Europa meridional. Entre los ejemplos de otras mutaciones que aparecen en la mayoría de las poblaciones, con una frecuencia de alrededor del 1 al $2 \%$, destacan las siguientes: G542X, G551D, R553X, W1282X y N1303K. Por último, para una población dada, existen mutaciones específicas de etnia que alcanzan frecuencias desde el 1\% hasta incluso el 7\% [25]. En la mayoría de las poblaciones, estas mutaciones corrientes cubren del 80 al 95\% de todos los genes RTFQ mutantes.

Se dispone de análisis comerciales que detectan sistemáticamente un conjunto de unas 30 mutaciones con una prevalencia superior al 0,5\%, la mayoría de las cuales se asocian a FQ clásica [26]. Una tasa de detección de mutaciones del $90 \%$ en una población específica significa que una mutación será identificada en ambos genes RTFQ en el $81 \%$ de los pacientes con FQ típica; se hallará una mutación en sólo un gen RTFQ en el $18 \%$, y ninguna mutación en ninguno de los genes RTFQ en el $1 \%$.

En el caso de una prueba del sudor limítrofe en un paciente con síntomas coherentes con FQ atípica, puede ser necesaria una extensa detección sistemática de mutaciones de ambos genes RTFQ para respaldar este diagnóstico. Sólo la secuenciación se aproximará a una sensibilidad del $100 \%$. Incluso si se detecta una mutación, su participación en la enfermedad puede no ser evidente: se desconocen las consecuencias funcionales de numerosas mutaciones del RTFQ; puede tratarse de polimorfismos [24].

\section{Bioanálisis de RTFQ: diferencia de potencial nasal transepitelial}

La FQ es una enfermedad causada por la ausencia o la disfunción de la proteína RTFQ apical, responsable de la secreción de cloruros inducida por AMPc. Además, se produce una corriente de entrada compensatoria y excesiva de sodio en las células epiteliales [2, 27]. Los bioanálisis de RTFQ miden las corrientes de iones epiteliales o su potencial de voltaje resultante en la superficie de la mucosa [28]. En consecuencia, estos análisis proporcionan una visión directa de la fisiología a nivel celular y del canal iónico, y se han elaborado para contribuir a resolver dilemas diagnósticos en pacientes atípicos, por inclusión o exclusión de una disfunción relacionada con RTFQ. Las pruebas pueden efectuarse en el epitelio respiratorio o el epitelio intestinal; son complejas y exigen un equipo y una experiencia especiales. El uso de la diferencia de potencial (DP) nasal como prueba diagnóstica de la FQ había sido aceptado ya en el consenso diagnóstico de Rosenstein y Cutting [29] en 1998. La DP se mide entre la mucosa nasal y la piel del antebrazo. Los detalles prácticos de esta prueba han sido publicados en otros lugares $[28,30]$. La DP basal proporciona una indicación del transporte de sodio a través del canal de sodio epitelial, sensible a amilorida. Seguidamente, se evalúa el efecto del bloqueo del canal de sodio epitelial por la superfusión de amilorida. Por último, se genera un considerable gradiente químico de cloruros a través de la membrana apical para medir la permeabilidad a los cloruros epiteliales.

La prueba ha sido introducida en la práctica clínica en varios grandes centros de $\mathrm{FQ}$, que han compilado sus propios valores de referencia. Con técnicos experimentados y una atención minuciosa a los detalles técnicos, la medición de la DP nasal puede ser estandarizada [31].

La DP nasal de un paciente con FQ clásica es fácilmente distinguible de la de una persona de control sana (fig. 1). En un paciente con FQ, la DP basal es más negativa, la respuesta a la amidorida más prolongada y la respuesta a soluciones exentas de cloruros y soluciones de isoproterenol, escasa o nula. En la FQ no clásica, la DP nasal puede ser limítrofe y todavía no se dispone de una opinión mayoritaria con respecto a lo que constituye exactamente un resultado anormal.

\section{Aspectos clínicos}

Tal como se ha mencionado, la FQ es una enfermedad multiorgánica. Los síntomas característicos de FQ son los siguientes: infecciones sinopulmonares crónicas, anomalías gastrointestinales y nutricionales, síndromes de pérdida de sal y anomalías genitales masculinas que resultan en azoospermia obstructiva (tabla 1). Casi todos los pacientes sufrirán por último la enfermedad sinopulmonar crónica. Alrededor del 90\% de los pacientes presentan insuficiencia pancreática. Los hombres postpuberales son infértiles.

\section{Enfermedad de las vías respiratorias inferiores}

La infección y la inflamación pulmonares crónicas con exacerbaciones intermitentes son el problema principal y limitan la duración y la calidad de vida de la mayoría de los pacientes con FQ. La infección pulmonar bacteriana asociada a un incremento de la respuesta inflama- 
Fig. 1. Medición de la diferencia de potencial (DP) nasal en una persona sana (a) y en una persona con FQ típica (b). En una persona sana, la DP basal es negativa $(-20$ a $30 \mathrm{mV}$ ), se eleva moderadamente tras la aplicación de amilorida y disminuye claramente tras la aplicación de una solución pobre en cloruros e isoproterenol. En un paciente con FQ típica, la DP basal es más negativa y la elevación tras la aplicación de amilorida es superior. No se observan cambios en la DP tras la aplicación de una solución pobre en cloruros e isoproterenol. De Boeck y cols. [55], con autorización del BMJ Publishing Group.
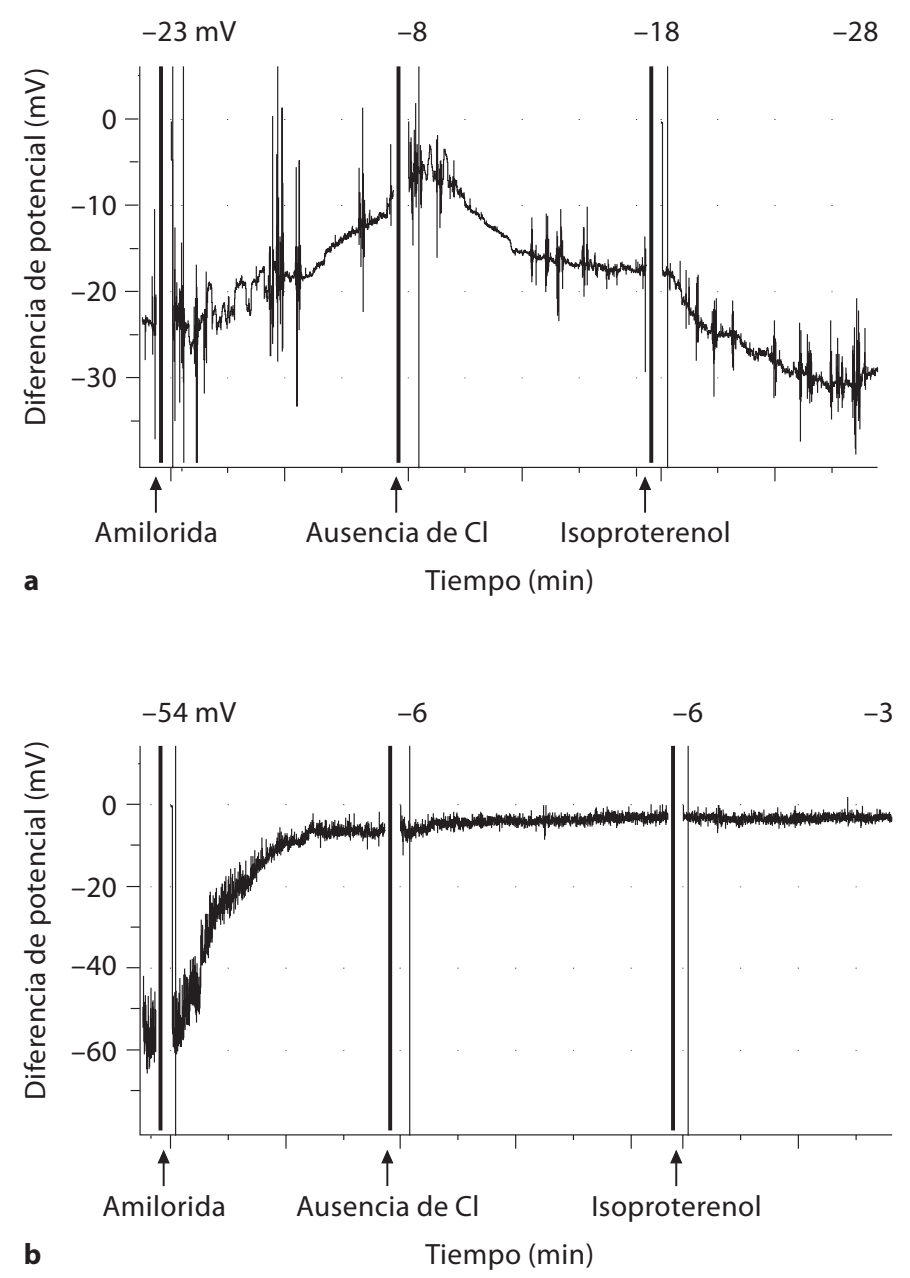

toria del hospedante se presenta a partir del inicio de la vida [32]. El balance anormal de sal y agua en las vías respiratorias causa la retención de secreciones viscosas y la obstrucción de las vías respiratorias. Este cuadro contribuye en gran medida a la perpetuación de la infección y la inflamación $[2,27]$. No obstante, no se conoce en todos sus extremos el vínculo exacto entre la disfunción del RTFQ y la infección bacteriana crónica [Donaldson y Boucher, páginas 103 a 109]. Las bacterias más característicamente relacionadas con la infección pulmonar de la FQ son: Staphylococcus aureus, Haemophilus influenzae y Pseudomonas aeruginosa. Aunque el curso de la neumopatía es invariablemente progresivo, el ritmo de la progresión depende de varios factores (tabla 2). El inicio de la infección crónica por Pseudomonas suele acompañarse de una declinación acelerada de la función pulmonar [33]. Como grupo, los pacientes con función pancreática conservada presentan una menor declinación de su función pulmonar [34]. La progresión de la enfermedad es influida por los factores siguientes: genotipo, genes modificadores, sexo, exposición al tabaco, estado nutricional deficiente, intensidad del tratamiento y otros [Cutting, páginas 112 a 116].

El curso clínico se caracteriza por exacerbaciones episódicas de la infección pulmonar. El incremento de la tos es el primer signo de exacerbación más corriente, y frecuentemente es subestimado. Otros posibles síntomas y signos son la disminución del apetito y la tolerancia al 
Tabla 2. Factores conocidos por influir sobre la progresión de la enfermedad

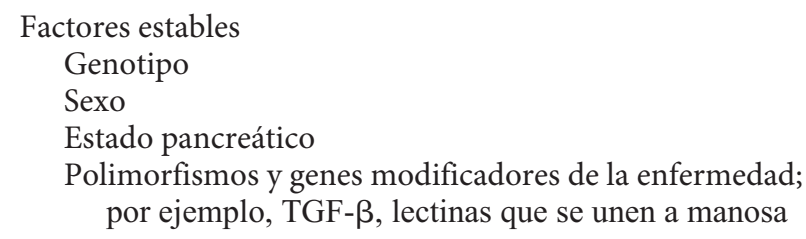
por ejemplo, TGF- $\beta$, lectinas que se unen a manosa

Factores potencialmente modificables

Edad en el momento del diagnóstico

Colonización crónica por $P$. aeruginosa o B. cepacia

Estado nutricional deficiente

Estado físico deficiente

Asistencia del centro de FQ

Intensidad del tratamiento y seguimiento

Exposición al humo de cigarrillos

Cumplimiento del tratamiento esfuerzo, la aparición de nuevos crepitantes a la auscultación, nuevos infiltrados en la radiografía de tórax y una declinación de la función pulmonar [35]. En su mayoría, los pacientes no presentan fiebre y a menudo faltan varios de esos datos. Las exacerbaciones tienden a seguir a una infección vírica [36]. A medida que la enfermedad progresa, la tos y la producción de esputo aumentan y la capacidad de esfuerzo llega a limitarse cada vez más.

Aunque las pruebas de función pulmonar son inicialmente normales, pronto se detecta una obstrucción periférica de las vías respiratorias. El $\mathrm{VEF}_{1}$, volumen máximo que puede ser espirado en 1 segundo, es el criterio de valoración más corrientemente utilizado para describir la progresión de la enfermedad [37]. Por último, aparece un cuadro de obstrucción y restricción mixto e hipoxia.

La distensión es el primer signo anormal en la radiografía de tórax, seguido al poco tiempo de retención de moco, típicamente en el lóbulo superior derecho. Este cuadro progresa en sentido de un incremento de las sombras lineales, dilatación bronquial, infiltrados, quistes y cor pulmonale. Se utilizan puntuaciones para cuantificar estas alteraciones [38].

Muchos pacientes presentan cierto grado de hiperreactividad de las vías respiratorias. Aunque la sensibilización alérgica al antígeno de Aspergillus aparece en numerosos pacientes, en el curso de la progresión de la enfermedad el síndrome desarrollado de aspergilosis broncopulmonar alérgica se observa en sólo el $10 \%$ de los pacientes [39]. La hemoptisis de entidad menor o mayor y el neumotórax son complicaciones en pacientes afecta- dos de la enfermedad avanzada. Por último, aparece insuficiencia respiratoria y muerte a menos que se realice un trasplante de pulmón.

Síntomas de las vías respiratorias superiores

Aunque casi todos los pacientes presentan signos radiográficos de pansinusitis, la sinusitis sintomática es infrecuente. La aparición de pólipos nasales es frecuente; pueden ocasionar una obstrucción nasal molesta y obligar a su resección [40].

\section{Páncreas}

La insuficiencia pancreática es la causa principal de incapacidad para medrar en pacientes con FQ. Aparece en alrededor del $90 \%$ de los pacientes y suele presentarse al año de edad [7]. Las deposiciones grasas y pastosas, la flatulencia, el dolor abdominal, el llanto excesivo y el aumento del apetito son síntomas típicos en pacientes que no reciben tratamiento. Predomina la malabsorción de las grasas. La falta de cumplimiento con la ingestión de enzimas pancreáticos sigue siendo la causa principal de dolor abdominal en pacientes con FQ. Algunos genotipos se asocian a una mejor conservación de la función pancreática. Estos pacientes son más propensos a episodios de pancreatitis aguda durante la adolescencia y la edad adulta [41]. La intolerancia relativa a la glucosa aumenta con la edad, y la diabetes mellitus relacionada con la FQ representa alrededor del $20 \%$ en adultos jóvenes. La diabetes mellitus se relaciona con un curso más desfavorable de la enfermedad antes y después del diagnóstico [42].

\section{Intestino}

La obstrucción del intestino delgado distal por meconio viscoso causa íleo meconial en alrededor del 15\% de los lactantes recién nacidos, afectados de FQ [4]. Más allá del periodo neonatal, todos los pacientes con FQ siguen siendo propensos a episodios similares de obstrucción intestinal, denominada síndrome de obstrucción intestinal distal [43]. El dolor abdominal espasmódico y la reducción de la producción de heces son los signos iniciales. Si no se identifican rápidamente, pueden progresar a la obstrucción intestinal total con distensión abdominal y vómito. La apendicitis sigue un curso atípico en los pacientes con FQ y puede dar lugar a un absceso abdominal en el cuadrante inferior derecho debido a perforación silente [44]. La invaginación es más frecuente. Aparece prolapso rectal recurrente en algunos lactantes afectados de FQ con malabsorción, principalmente antes del inicio del tratamiento. 


\section{Vías hepatobiliares}

La colestasis neonatal puede conducir al diagnóstico de FQ; sin embargo, no se asocia a hepatopatía en la vida posterior [5]. En numerosos pacientes con FQ aparece una elevación asintomática de las enzimas hepáticas. Unos pocos pacientes presentan una cirrosis biliar grave y requieren trasplante hepático o fallecen por complicaciones de hipertensión portal e hiperesplenismo [45]. Signos clínicos como esplenomegalia y hepatomegalia palpable con borde firme permiten suponer la existencia de una hepatopatía. Aunque la biopsia hepática proporciona la información más confiable, no se practica frecuentemente debido a su carácter invasivo. En la mayoría de los centros se realiza cada año una ecografía hepática para determinar la puntuación de Westaby [46], con objeto de detectar precozmente a pacientes con hepatopatías significativas.

\section{Esófago}

Los lactantes con FQ presentan a menudo reflujo gastroesofágico [47]. La fisioterapia torácica en posición cabeza abajo puede empeorar el reflujo. También es corriente el reflujo gastroesofágico en pacientes con FQ de mayor edad; la distensión, la tos y el incremento de los esfuerzos inspiratorios pueden propiciar el reflujo gastroesofágico.

\section{Nutrición}

A medida que progresa la enfermedad, el estado nutricional de los pacientes afectados de FQ tiende a empeorar: pueden presentar estatura baja, peso más liviano y retraso de la maduración sexual. La conservación de una talla normal y un incremento del peso justifica la realización de un gran esfuerzo. Los pacientes con FQ presentan malabsorción, tienen incrementadas sus necesidades calóricas para combatir la infección crónica y pueden presentar un índice metabólico intrínsecamente más elevado [48]. Son propensos a deficiencias de vitaminas liposolubles, oligoelementos y ácidos grasos esenciales [49]. Presentan anomalías en el metabolismo de los ácidos grasos esenciales [50; Strandvik, p. 132].

\section{Otros sintomas}

El retraso de la maduración sexual es más corriente. Los hombres postpuberales son casi siempre estériles. En las mujeres disminuye la fertilidad, y el embarazo puede constituir una amenaza para la salud, especialmente cuando la función pulmonar está deteriorada [51].

La pérdida excesiva de sal a través del sudor puede dar lugar a deshidratación aguda [9]. En lactantes afectados de FQ, una ingestión pobre en sal, en ocasiones combinada con una pérdida excesiva de sal durante los días cálidos, puede causar alcalosis metabólica [9].

El cor pulmonale es una consecuencia de neumopatía avanzada e hipoxia prolongada.

Se observan dedos en palillo de tambor en la mayoría de los pacientes con neumopatía o hepatopatía avanzada. La osteoporosis aparece en adultos jóvenes [52]. Con el tratamiento más intensivo de la infección crónica, la típica osteortropatía hipertrófica es ahora muy infrecuente.

\section{Problemas psicológicos}

Un número creciente de personas con FQ desempeñan vidas activas y productivas a pesar de su enfermedad y su carga terapéutica. Sin embargo, la salud frágil y el futuro incierto inducen en muchas un riesgo de problemas emocionales psicológicos. Encontrar trabajo, una pareja y participar en la 'vida corriente' no es fácil cuando se sufre de una enfermedad potencialmente mortal. A medida que el paciente se hace mayor se añaden nuevas complicaciones, y la complejidad y el coste del tratamiento no hacen más que aumentar. No obstante, a menudo, la carga psicológica percibida no es proporcional al estado de salud objetivo de la persona; es decir, puede aparecer depresión en pacientes que, según su médico, evolucionan de un modo perfectamente favorable [53, 54].

Los padres, así como los hermanos, de pacientes con FQ tienen un mayor riesgo de problemas psicológicos debido al estrés emocional, los ingresos en hospitales, la carga financiera, el tiempo necesario para cuidar al niño enfermo y la sensación de abandono.

\section{FQ atípica o FQ no clásica}

Hace mucho tiempo se detectaban ya pacientes con FQ y función pancreática conservada, lo que demostraba la variabilidad del espectro de la enfermedad. Con el descubrimiento del gen $R T F Q$ se ha hecho cada vez más evidente que los síntomas característicos de FQ, que se inician en una etapa precoz de la vida y se asocian a la FQ clásica, representan sólo la punta del iceberg de todos los síntomas que pueden vincularse a la disfunción del RTFQ. Hay pacientes con síntomas muy leves y que inician la enfermedad sólo durante la adolescencia o la edad adulta, y pacientes con sólo una característica clínica única; por ejemplo, pancreatitis recurrente, colangitis esclerosante, bronquiectasia 'idiopática' o infertilidad masculina. Las dos últimas categorías se describen como FQ atípica o no clásica. En la mayoría, el valor de los cloruros en el sudor es equívoco, es decir, 30 a $60 \mathrm{mEq} / \mathrm{l}$. La declaración norteamericana de consenso de Rosenstein y Cutting [29] 
redefinió los criterios para el diagnóstico de FQ teniendo en cuenta este conocimiento reciente. Afirmaron que un diagnóstico de FQ se establece en pacientes que presentan uno o más rasgos fenotípicos característicos, $o$ un hermano con FQ, $o$ un resultado de la prueba de detección sistemática neonatal positiva, más datos de laboratorio de anomalía del RTFQ por el resultado de la prueba del sudor claramente positiva $o$ dos mutaciones de RTFQ causantes de enfermedad, $o$ una medición anormal de la DP nasal [29]. No obstante, esta definición no distingue entre los pacientes con FQ clásica y los pacientes con fenotipos más leves. En un reciente informe de consenso europeo, los autores han sido más pragmáticos: el término FQ clásica se reserva para los pacientes con síntomas clínicos y una prueba del sudor positiva, mientras que el término FQ atípica o no clásica se reserva para los pacientes en quienes la prueba del sudor es equívoca o normal y el diagnóstico es respaldado por herramientas diagnósticas más recientes, es decir, dos mutaciones causantes de enfermedad o una DP nasal anormal [55]. Aunque esta clasificación es útil, no debe aplicarse con demasiada rigidez. El fenotipo FQ es en realidad un continuo, y se produce un solapamiento entre categorías.

La etiqueta diagnóstica de FQ, que describe una enfermedad potencialmente mortal, conlleva una enorme carga emocional y puede ser un inconveniente para los pacientes; por ejemplo, para propósitos de empleo o contrato de seguros. En consecuencia, en pacientes con presentación atípica debe desatacarse que no sufren de FQ clásica. Es incluso más apropiado que pacientes con manifestaciones patológicas en sólo un órgano sean designados y clasificados por la propia manifestación de la enfermedad en lugar de por el término FQ atípica; por ejemplo, esterilidad debido a la ausencia bilateral del vas deferens o colangitis esclerosante, u otro artículo de la lista diagnóstica de la OMS [56]. El seguimiento de estos pacientes es necesario por dos motivos: en primer lugar, las características clínicas en el paciente individual pueden cambiar en el trascurso del tiempo; por ejemplo, alguien con ausencia bilateral congénita aislada del vas deferens puede presentar infecciones pulmonares y, en segundo lugar, los médicos tienen que extender y compartir su conocimiento sobre lo que significa disfunción del RTFQ durante todo el periodo de vida de un paciente.

En pacientes con cloruros en el sudor indeterminados, sólo una mutación identificada y una DP nasal poco concluyente plantean el reto diagnóstico real: en este momento no pueden ser clasificados porque la disfunción del RTFQ no ha sido demostrada claramente. Existen por lo menos portadores de FQ. En presencia de síntomas persistentes precisan de un seguimiento estructurado en un centro apropiado y de tratamiento sintomático. El asesoramiento genético es importante para estos pacientes y sus familias. Debe recogerse información a largo plazo sobre este tipo de paciente, seguido probablemente de un conocimiento perfeccionado: la combinación de una sola mutación más varios genes modificadores desfavorables es una de las posibilidades [55].

\section{Asesoramiento}

Debido a la complejidad que representa aconsejar a las familias y a los allegados, las emociones implicadas y el riesgo de que la información impartida correctamente sea mal entendida, interpretada exageradamente o recordada de manera incompleta, el especialista en genética clínica debe proporcionar asesoramiento. También es beneficioso disociar el asesoramiento de la familia y la asistencia del paciente.

\section{Padres de pacientes con FQ}

Los padres de niños con FQ son heterocigotos obligados. Para cualquier embarazo subsiguiente de estos padres existe un riesgo de tipo 1 de 4 de que el niño esté afectado. Si los padres desean embarazos ulteriores, deben tener acceso a las pruebas prenatales. Cuando ambas mutaciones son conocidas, el análisis de las mutaciones se efectúa en células fetales obtenidas por muestreo de las vellosidades coriónicas o amniocentesis [57]. Cuando sólo se ha identificado una de las mutaciones de RTFQ causante de FQ, una prueba de ADN adicional no es imperativa. El diagnóstico prenatal puede efectuarse también por análisis de segregación de polimorfismos dentro del gen $R T F Q$ o vinculado al mismo. Debido al estrés emocional asociado a la decisión de interrumpir el embarazo, muchos padres optan por abstenerse de embarazos ulteriores $[58,59]$.

\section{Hermanos de pacientes con FQ}

Los síntomas de FQ pueden ser muy variables, incluso dentro de una misma familia. En consecuencia, la FQ debe excluirse siempre en los hermanos, no sobre bases clínicas sino por medio de pruebas formales. En el caso de hermanos pequeños se recomienda excluir la FQ por medio de la prueba del sudor en lugar de utilizar el análisis de mutaciones. No es deseable que los menores sepan si son o no portadores; sólo es importante en hermanos con respecto a decisiones de reproducción. Existe la preocupación de que los padres puedan sobre- 
proteger o, de lo contrario, estigmatizar, a los portadores $[60]$.

\section{Parientes de padres de niños con FQ}

Los parientes de padres de niños con FQ presentan un mayor riesgo de portar una mutación de RTFQ y deben ser informados al respecto. Algunos especialistas en genética recomiendan informar del estado de riesgo a la pareja en lugar de hacerlo individualmente [61]; sin embargo, en momentos y situaciones de cambio de parejas sexuales, este procedimiento llega a ser complejo. Cuando el estado de portador no se detecta en un individuo, disminuye su riesgo de tener un hijo con $\mathrm{FQ}$, si bien dicho riesgo nunca puede excluirse por completo; las pruebas de detección sistemática sólo consideran las mutaciones más prevalentes junto a las mutaciones expresadas en el paciente con FQ, siempre que no se hubiesen incluido en el grupo de detección sistemática.

\section{Conclusión}

La FQ es una compleja enfermedad multiorgánica causada por una disfunción de la proteína RTFQ.

En la inmensa mayoría de los casos se produce la pérdida total de la función del RTFQ y el diagnóstico de FQ es evidente; el cuadro clínico es obvio y los resultados de la prueba del sudor confirman el diagnóstico clínico. Habitualmente se identifica una mutación de RTFQ causante de enfermedad que es común en ambos genes RTFQ. En algunos pacientes, el cuadro clínico es mucho más leve o incluso queda limitado a un solo órgano. Son los llamados pacientes con FQ atípica. En la mayoría de los casos, el análisis de las mutaciones de $R T F Q$ y los bioanálisis de la función de la proteína RTFQ respaldarán el diagnóstico. Debido a su rareza, en ocasiones no existen pruebas de que las mutaciones de RTFQ halladas en tales pacientes sean, de hecho, causantes de enfermedad. Nuestro conocimiento acerca del pronóstico a largo plazo de estos casos atípicos es insuficiente. Estos pacientes no presentan la FQ clásica y tienen que ser informados claramente al respecto.

Numerosos síntomas diferentes pueden constituir la primera manifestación de $\mathrm{FQ}$, siendo los más frecuentes un niño con tos crónica y deposiciones sueltas. Un grado elevado de sospecha es la mejor actitud para no obviar el diagnóstico, especialmente en los casos más leves. La prueba del sudor por iontoforesis de pilocarpina sigue siendo la prueba de elección. La concentración de cloruros en el sudor es $>60 \mathrm{mmol} / \mathrm{l}$ en los pacientes con FQ.
Aunque se trata de una prueba simple, por motivos de exactitud diagnóstica debe realizarse en un laboratorio experimentado. En casos difíciles, el análisis del RTFQ y los bioanálisis de RTFQ representan un apoyo adicional. El diagnóstico precoz es necesario para retrasar la progresión de la enfermedad.

La infección y la inflamación sinopulmonares bacterianas progresivas crónicas con exacerbaciones intermitentes son las manifestaciones patológicas más típicas. El $90 \%$ de los pacientes presentan insuficiencia pancreática. Los hombres postpuberales son estériles. Durante su vida, los pacientes con FQ conllevan el riesgo de manifestaciones y complicaciones patológicas en numerosos órganos diferentes: senos, pulmones, páncreas, hígado, intestino, esófago, huesos, articulaciones, etc. La mezcla compleja de posibles manifestaciones patológicas confiere un carácter único a cada paciente. A medida que se hace mayor, el número de complicaciones tiende a incrementarse; por ejemplo, el 20\% de pacientes adultos jóvenes presentan diabetes mellitus relacionada con la FQ.

La FQ clásica es un trastorno potencialmente mortal, e incluso con el tratamiento y el seguimiento más intensivo la mediana de supervivencia actual gira en torno a 34 años. Este hecho confiere un enorme estrés psicológico a los pacientes y a sus familias.

El asesoramiento para prevenir la recurrencia de la enfermedad en los hermanos y en la familia ampliada es importante pero complejo. 


\section{Bibliografía}

1 Report of a Joint Meeting of WHO/ECFTN/ ICF/(M)A/ECFS: The Molecular Genetic Epidemiology of Cystic Fibrosis. Geneva, WHO, 2006. http//:www.who.int/genomics/ publications/en/

$\checkmark 2$ Boucher RC: Regulation of airway surface liquid volume by human airway epithelia. Pflugers Arch 2003;445:495-498.

3 Rosenstein BJ: Diagnostic methods; in Hodson M, Geddes D (eds): Cystic Fibrosis. London, Arnold, 2006, vol 2, pp 177-188.

4 Mushtaq I, Wright VM, Drake DP, et al: Meconium ileus secondary to cystic fibrosis. The East London experience. Pediatr Surg Int 1998;13:365-369.

5 Shapira R, Hadzic N, Francavilla R, et al: Retrospective review of cystic fibrosis presenting as infantile liver disease. Arch Dis Child 1999;81:125-128.

6 6 Lai HJ, Cheng Y, Farrell PM: The survival advantage of patients with cystic fibrosis diagnosed through neonatal screening: evidence from the United States Cystic Fibrosis Foundation registry data. J Pediatr 2005; 147 : S57-S63.

7 Waters DL, Dorney SF, Gaskin KJ, et al: Pancreatic function in infants identified as having cystic fibrosis in a neonatal screening program. N Engl J Med 1990;322:303-308.

-8 Abman SH, Accurso FJ, Butler-Simon N, et al: Role of respiratory syncytial virus in early hospitalizations for respiratory distress of young infants with cystic fibrosis. J Pediatr 1988; 113:826-830.

-9 Sojo A, Rodriguez-Soriano J, Vitoria JC, et al: Chloride deficiency as a presentation or complication of cystic fibrosis. Eur J Pediatr 1994;153:825-828.

10 Chillon M, Casals T, Mercier B, et al: Mutations in the cystic fibrosis gene in patients with congenital absence of the vas deferens. N Engl J Med 1995;332:1475-1480.

-11 Muniz AE, Bartle S, Foster R: Edema, anemia, hypoproteinemia, and acrodermatitis enteropathica: an uncommon initial presentation of cystic fibrosis. Pediatr Emerg Care 2004;20:112-114.

12 Grosse SD, Boyle CA, Botkin JR, et al: Newborn screening for cystic fibrosis: evaluation of benefits and risks and recommendations for state newborn screening programs. MMWR Recomm Rep 2004;53:1-36.

13 Scotet V, de Braekeleer M, Roussey M, et al: Neonatal screening for cystic fibrosis in Brittany, France: assessment of 10 years' experience and impact on prenatal diagnosis. Lancet 2000;356:789-794.

$\checkmark 14$ Gibson LE, Cooke RE: A test for concentration of electrolytes in sweat in cystic fibrosis of the pancreas utilizing pilocarpine by iontophoresis. Pediatrics 1959;23:545-549.

15 Orenstein DM, Winnie GB, Altman H: Cystic fibrosis: a 2002 update. J Pediatr 2002; 140:156-164.
16 LeGrys VA: Sweat testing for the diagnosis of cystic fibrosis: practical considerations. J Pediatr 1996;129:892-897.

17 Guidelines for the performance of the sweat test for the investigation of cystic fibrosis in the UK. Report from the multi-disciplinary working group. July 2002 (http//:www.acb. org.uk).

18 Di Sant'Agnese PA, Darling RC, Perera GA, Shea E: Abnormal electrolyte composition of sweat in cystic fibrosis of the pancreas; clinical significance and relationship to the disease. Pediatrics 1953;12:549-563.

19 Kirk JM, Keston M, McIntosh I, Essa S: Variation of sweat sodium and chloride with age in cystic fibrosis and normal populations: further investigations in equivocal cases. Ann Clin Biochem 1992;29:145-152.

20 Lebecque P, Leal T, De Boeck C, et al: Mutations of the cystic fibrosis gene and intermediate sweat chloride levels in children. Am J Respir Crit Care Med 2002;165:757-761.

21 National Committee for Clinical Laboratory Standards (NCCLS): Sweat Testing: Sample Collection and Quantitative Analysis. Approved guideline C34-A2. Wayne, NCCLS, 2006.

22 Highsmith WE, Burch LH, Zhou Z, et al: A novel mutation in the cystic fibrosis gene in patients with pulmonary disease but normal sweat chloride concentrations. N Engl J Med 1994;331:974-980.

23 Cystic Fibrosis Genotype-Phenotype Consortium: Correlation between genotype and phenotype in patients with cystic fibrosis. $\mathrm{N}$ Engl J Med 1993;329:1308-1313.

24 http://genet.sickkids.on.ca/cgi-bin/WebObjects/MUTATION

25 Schaedel C, Hjelte L, de Monestrol I, et al: Three common CFTR mutations should be included in a neonatal screening programme for cystic fibrosis in Sweden. Clin Genet 1999;56:318-322.

26 Dequeker E, Cuppens H, Dodge J, et al: Recommendations for quality improvement in genetic testing for cystic fibrosis. European Concerted Action on Cystic Fibrosis. Eur J Hum Genet 2000;8(suppl 2):S2-S24.

27 Donaldson SH, Boucher RC: Update on pathogenesis of cystic fibrosis lung disease. Curr Opin Pulm Med 2003;9:486-491.

28 Knowles MR, Paradiso AM, Boucher RC: In vivo nasal potential difference: techniques and protocols for assessing efficacy of gene transfer in cystic fibrosis. Hum Gene Ther 1995;6:445-455.

29 Rosenstein BJ, Cutting GR: The diagnosis of cystic fibrosis: a consensus statement. Cystic Fibrosis Foundation Consensus Panel. J Pediatr 1998;132:589-595.

30 Schuler D, Sermet-Gaudelus I, Wilschanski $\mathrm{M}$, et al: Basic protocol for transepithelial nasal potential difference measurements. J Cyst Fibros 2004;3(suppl 2):151-155.
31 Standaert TA, Boitano L, Emerson J, et al: Standardized procedure for measurement of nasal potential difference: an outcome measure in multicenter cystic fibrosis clinical trials. Pediatr Pulmonol 2004;37:385-392.

32 Armstrong DS, Grimwood K, Carlin JB, et al: Lower airway inflammation in infants and young children with cystic fibrosis. Am J Respir Crit Care Med 1997;156:1197-1204.

33 Frederiksen B, Koch C, Hoiby N: Antibiotic treatment of initial colonization with Pseudomonas aeruginosa postpones chronic infection and prevents deterioration of pulmonary function in cystic fibrosis. Pediatr Pulmonol 1997;23:330-335.

34 Corey M, Edwards L, Levison H, Knowles M: Longitudinal analysis of pulmonary function decline in patients with cystic fibrosis. J Pediatr 1997;131:809-814.

35 Rosenfeld M, Emerson J, Williams-Warren J, et al: Defining a pulmonary exacerbation in cystic fibrosis. J Pediatr 2001;139:359-365.

36 Collinson J, Nicholson KG, Cancio E, et al: Effects of upper respiratory tract infections in patients with cystic fibrosis. Thorax 1996; 51:1115-1122.

37 Corey M, McLaughlin FJ, Williams M, Levison $\mathrm{H}$ : A comparison of survival, growth, and pulmonary function in patients with cystic fibrosis in Boston and Toronto. J Clin Epidemiol 1988;41:583-591.

-38 Brasfield D, Hicks G, Soong S, Tiller RE: The chest roentgenogram in cystic fibrosis: a new scoring system. Pediatrics 1979;63:24-29.

39 Mastella G, Rainisio M, Harms HK, et al: Allergic bronchopulmonary aspergillosis in cystic fibrosis. Eur Respir J 2001;17:10521053.

40 Jorissen MB, De Boeck K, Cuppens H: Genotype-phenotype correlations for the paranasal sinuses in cystic fibrosis. Am J Respir Crit Care Med 1999;159:1412-1416.

-41 De Boeck K, Weren M, Proesmans M, Kerem E: Pancreatitis among patients with cystic fibrosis: correlation with pancreatic status and genotype. Pediatrics 2005; 115:e463e469.

-42 Moran A, Hardin D, Rodman D, et al: Diagnosis, screening and management of cystic fibrosis related diabetes mellitus: a consensus conference report. Diabetes Res Clin Pract 1999;45:61-73.

43 Mascarenhas MR: Treatment of gastrointestinal problems in cystic fibrosis. Curr Treat Options Gastroenterol 2003;6:427-441.

44 Martens M, De Boeck K, Van Der Steen K, et al: A right lower quadrant mass in cystic fibrosis: a diagnostic challenge. Eur J Pediatr 1992;151:329-331. 
45 Sokol RJ, Durie PR: Recommendations for management of liver and biliary tract disease in cystic fibrosis. Cystic Fibrosis Foundation Hepatobiliary Disease Consensus Group. J Pediatr Gastroenterol Nutr 1999;28(suppl 1):S1-S13.

46 Williams SG, Evanson JE, Barrett N, et al: An ultrasound scoring system for the diagnosis of liver disease in cystic fibrosis. J Hepatol 1995;22:513-521.

47 Heine RG, Button BM, Olinsky A, et al: Gastro-oesophageal reflux in infants under 6 months with cystic fibrosis. Arch Dis Child 1998;78:44-48.

48 Sinaasappel M, Stern M, Littlewood J, et al: Nutrition in patients with cystic fibrosis: a European Consensus. J Cyst Fibros 2002;1: 51-75.
49 Roulet M, Frascarolo P, Rappaz I, Pilet M: Essential fatty acid deficiency in well nourished young cystic fibrosis patients. Eur J Pediatr 1997;156:952-956.

50 Strandvik B, Gronowitz E, Enlund F, et al: Essential fatty acid deficiency in relation to genotype in patients with cystic fibrosis. J Pediatr 2001;139:650-655.

51 Edenborough FP, Stableforth DE, Webb AK, et al: Outcome of pregnancy in women with cystic fibrosis. Thorax 1995;50:170-174.

52 Conway S: Osteoporosis is cystic fibrosis. J Cyst Fibros 2003;2:161-162.

53 Elgudin L, Kishan S, Howe D: Depression in children and adolescents with cystic fibrosis: case studies. Int J Psychiatry Med 2004;34: 391-397.

54 Kotwicki RJ, Condra L, Vermeulen L, et al: Assessing the quality of life in children with cystic fibrosis. WMJ 2001;100:50-54.

55 De Boeck K, Wilschanski M, Castellani C, et al: Cystic fibrosis: terminology and diagnostic algorithms. Thorax 2005.
6 Classification of cystic fibrosis and related disorders. J Cyst Fibros 2002;1:5-8.

57 Richards CS, Grody WW: Prenatal screening for cystic fibrosis: past, present and future. Expert Rev Mol Diagn 2004;4:49-62.

58 Evers-Kiebooms G, Denayer L, Cassiman JJ, Van den Berghe H: Family planning decisions after the birth of a cystic fibrosis child: the impact of prenatal diagnosis. Scand J Gastroenterol 1988;23:38-46.

59 Mischler EH, Wilfond BS, Fost N, et al: Cystic fibrosis newborn screening: impact on reproductive behavior and implications for genetic counseling. Pediatrics 1998;102:4452.

60 Clarke A: The genetic testing of children. Working Party of the Clinical Genetics Society (UK). J Med Genet 1994;31:785-797.

61 Super M, Schwarz MJ, Malone G, et al: Active cascade testing for carriers of cystic fibrosis gene. BMJ 1994;308:1462-1467. 